\title{
A Identidade da Mulher na Modernidade
}

\author{
(Women's Identity in Modernity)
}

\author{
Josênia Antunes VIEIRA \\ (Universidade de Brasília)
}

\begin{abstract}
This paper deals with changes in the constitution of women's identity in relation to new discourse practices. These are the result of changes in discourse orders due to economic globalization. These changes have altered people's lives and their intimacy, thus modifying their way of being. In this sense, changes in social relations have brought about difficulties in the construction of female identity. Thus, this article, based on critical discourse analysis, seeks to discuss the following issues: the social construction of women's identity; technology and the media as fragmentary agents in women's identity; spatialization in female discourse; the discourse of the body in identity self-realization; women's identity vis à vis transformations in sexuality; the construction of female identity in the family; the identity issue and education and, finally, the world of work as a structuring element in female identity.
\end{abstract}

KEY-WORDs: Change; Female Identit; Critical Discourse Analysis.

REsumo: $O$ artigo trata das mudanças na constituição da identidade da mulher diante das novas práticas discursivas, produto das modificações nas ordens do discurso, resultado da globalização da economia. Essas mudanças alteraram a vida e a intimidade das pessoas, modificando-lhes o modo de ser. Assim, as transformações das relações sociais trazem dificuldades para a construção identitária feminina. Para isso, o artigo discute, à luz da análise de discurso crítica, os tópicos: a construção social da identidade da mulher; o papel do sujeito; a tecnologia e a mídia como agentes fragmentadores da identidade da mulher; a espacialização no discurso feminino; o discurso do corpo na auto-realização identitária; a identidade da mulber diante das transformações da sexualidade; a construção da identidade do gênero feminino na família; a questão identitária e o ensino e, por fim, o trabalho como força estruturante da identidade feminina.

PalavRas-CHave: Mudanças; Identidade Feminina; Análise de Discurso Crítica. 


\section{Introdução}

O mundo virou de cabeça para baixo. Esse tem sido o refrão familiar no período pós-moderno. Afinado no mesmo tom, Giddens declara (2000: 5.) "para o bem ou para o mal, somos impelidos rumo a uma nova ordem global que ninguém compreende plenamente, mas cujos efeitos se fazem sentir sobre todos nós: a globalização".

Nesse contexto, as nações transformam-se rapidamente e, ao mesmo tempo, que se libertam dos vínculos nacionais, os expandem no âmbito internacional. Por essa razão, o sujeito, ao produzir textos, tem de incluir ordens do discurso que contemplem não apenas esses níveis, mas também o societal e o global, acrescenta Fairclough (1997: 300). Por essa razão, as instituições e os indivíduos, sob pressão de modelos e de práticas sociais específicas nessas esferas, negociam constantemente suas identidades por meio da mediação discursiva.

Atento a esse fato, Fairclough (1997: 300) chama atenção para a possibilidade de identificação de ordens do discurso no nível global. Acredita que a globalização econômica, política e cultural desempenha papel central nas mudanças sociais contemporâneas e reitera a relevância do discurso e de suas práticas no desenvolvimento global. Afirma também que as ordens do discurso das diferentes nações estão interconectadas e essas redes emergentes de práticas, decorrentes de uma nova ordem global do discurso, constituem o horizonte contra o qual as ordens do discurso de uma nação - estado particular - são formadas e transformadas.

Ao antever essa nova ordem do discurso, é preciso considerar que a globalização tem a ver com a tese de que agora vivemos todos em um mundo único. Sob muitos aspectos, essas práticas discursivas não são apenas comuns a toda a comunidade internacional, mas também novas e revolucionárias, pois a mudança mundial não é um fenômeno singular e único, mas envolve um conjunto complexo de processos que interfere na definição das novas ordens do discurso. É um domínio novo e absoluto que desfruta de poder hegemônico, instituindo novas práticas discursivas que alargam fronteiras e aumentam o poder global.

Em decorrência da nova ordem econômica, os mercados e, sobretudo, os sujeitos passam por profundas transformações e muitos as qualificam somente em termos das alterações da economia. Mas, ao contrário, elas 
implicam mudanças políticas, culturais e tecnológicas, uma vez que recebem influências, principalmente, do avançado sistema de comunicação. Hoje, centenas de satélites transmitem informações que permitem a comunicação instantânea de um lado a outro do mundo, sendo um dos fatores que mais contribui para inovar a estrutura de vida das mulheres e dos homens, independentemente de sua condição de letramento, de sua classe social ou de sua nacionalidade.

Essa alteração global não é apenas um fenômeno externo, ao contrário, influencia aspectos da intimidade dos sujeitos, modificando vidas e o modo de ser de cada um deles. Em conseqüência, as relações sociais transformam-se em sua essência, trazendo dificuldades para a definição identitária em geral e, em particular, para o gênero feminino e, mesmo que as identidades estejam em contínua construção e, por mais rápido que seja esse processo, existe descompasso em relação a essa mudança e à evolução global que dificultarão a construção identitária da mulher da pós-modernidade.

Dessas diferenças resultam dificuldades para o sexo feminino construir uma nova identidade. As tentativas da mulher contemporânea de definir o que parece ser o seu verdadeiro perfil identitário compõem o objeto deste artigo, cujo intuito é discutir as questões da identidade feminina e, ao mesmo tempo, pretende desvelar a hegemonia do discurso masculino na construção da identidade da mulher. Tenta também alargar o espaço discursivo para a emergência e para o desenvolvimento de discursos divergentes nas questões que envolvem as diferenças e as desigualdades do gênero, muitas vezes imperceptíveis.

Para alcançar esse propósito, o artigo discute, à luz da Análise de Discurso Crítica, os seguintes tópicos: a construção social da identidade da mulher: o papel do sujeito; a tecnologia e a mídia como agentes fragmentadores da identidade da mulher; a espacialização no discurso feminino; o discurso do corpo na auto-realização identitária; a identidade da mulher diante das transformações da sexualidade; a construção da identidade de gênero feminino na família; a questão identitária e o ensino; o trabalho como força estruturante da identidade feminina.

Deve ainda ser acrescentado que uma perspectiva crítica para tratar da identidade do gênero feminino defende também um propósito político e emancipatório. A palavra crítica, aqui, transcende o sentido comum do 
termo, considerando que pretende identificar, explicitar e provocar resistência àquilo que é senso comum no discurso sobre a mulher.

\section{A construção social da identidade da mulher: o papel do sujeito}

Nesta virada de século, as verdades, os limites e as noções sobre o sujeito alteraram-se profundamente. A ausência de um paradigma preponderante para defini-lo provoca o aparecimento de complexa rede de sentidos, mantida pelo discurso, cujo papel é construir a identidade do sujeito contemporâneo. As diferentes ordens do discurso, responsáveis pelas mudanças do sujeito, constituem a identidade feminina e, por estarem submissas a momentos históricos específicos, abrigam experiências particulares, emoções e vivências culturais que permitem a construção social da subjetividade da mulher.

Cada época, a seu modo, influencia o sujeito na forma de pensar e de agir. Ao passarmos os olhos pela história da humanidade, percebemos que alguns períodos marcaram profundamente a construção da identidade, como é o caso da excessiva valorização espiritual na Idade Média, da descoberta dos valores humanos no Renascimento, ou, ainda, da exacerbada atenção à atividade intelectual no Iluminismo. Além disso, para a constituição de si mesmo, do self, o sujeito agrega tendências específicas do conhecimento, reduzindo-se, por exemplo, a estímulos e respostas na concepção behaviorista, ou a determinismo social na perspectiva histórica e antropológica, assimilando, em sua construção identitária, particularidades e valores específicos de cada momento.

Nesse sentido, Giddens (2002) defende que a pós-modernidade tornou o sujeito passível de fragmentação e de dispersão, sendo a subjetividade reduzida a valor instrumental. Ainda, em virtude do acentuado desenvolvimento tecnológico, o sujeito pós-moderno aumenta velozmente a interação discursiva com a máquina enquanto, inversamente, a diminui com o gênero humano.

Assim, em virtude das mudanças ocorridas na concepção de sujeito, muitas discussões têm surgido sobre o seu papel na construção da identidade contemporânea e, considerando que o limiar entre o conceito de sujeito e o de identidade é sutil e, muitas vezes imperceptível, desejamos 
saber precisamente qual o papel do sujeito na definição da identidade. Como comporta-se? De modo independente, livre de qualquer influência, ou assujeitado ao contexto social e ao discurso do outro?

Antes de responder a essas questões, devemos ressaltar mais uma vez que o sujeito não representa apenas um momento particular, antes é constituído por uma série de eventos discursivos que acontecem na vida de uma pessoa. Resulta de percurso histórico único e singular de cada sujeito, sendo construído com emoções, com perdas e ganhos, com crenças, com juízos e valores, que são agregados ao longo de sua história de vida. Mas, o sujeito não é apenas um espectador de sua vida, ele recebe influências, porém, ao mesmo tempo, interfere na construção histórica de sua subjetividade. Para ratificar o que foi dito, trazemos a voz de Emília Pedro (1997: 160) que, com propriedade, declara:

Entretanto, nós não somos usuários passivos de fontes de discursos pré-fabricados. É verdade que elas existem e limitam-nos e formam o que nós dizemos, mas quando nós falamos, nós as usamos sempre em combinações novas e variadas. Nesse sentido, nós podemos ser considerados autores genuínos.

No que concerne à discussão do papel do sujeito na construção da identidade da mulher, devemos ressaltar que é por meio da negociação da identidade e da diferença que o sujeito deve ser estabelecido. Nesse sentido, Fairclough (1997: 296) critica a dominação e o poder de certas classes de sujeitos constituídos sobre outros e contribui com a concepção de que a construção do sujeito do discurso resulta de um processo ideológico, conceito defendido pela Análise de Discurso Crítica.

Assim, identidade e diferença são, para ele, dois lados da mesma moeda e representam atualmente os maiores dilemas da vida social. É aceito, então, que a identidade social da mulher não é unitária, mas que resulta de diferenças. Desse modo, podemos concebê-la como produto da negociação externa da diferença com outros sujeitos, estabelecendo um contínuo, nessa negociação, cujo propósito permanente é a constituição do self.

Woodward (1997: 1) compartilha também do ponto de vista de que identidade e diferença são palavras de ordem na discussão da constituição da identidade. Nessa perspectiva, a heterogeneidade textual é o espaço privilegiado para essa negociação. Sobre isso, Fairclough (1997: 298), com precisão, declara: 
Heterogeneidade textual é a presença e trabalha através das contradições. Identidade, relações sociais e conhecimento estão textualmente enlaçados. $\mathrm{O}$ mundo, os sujeitos sociais, as relações sujeito-sujeito e as relações mundo-sujeito são todos construídos nos textos em modos contraditórios. Heterogeneidade textual é também, entretanto, a presença e, trabalhando através dos dilemas-modo de experiência e reação, tenta mover-se além dessas contradições. Textos são lugares para a luta social.

Se olharmos a heterogeneidade do ponto de vista da perspectiva da identidade, o texto é o lugar privilegiado para a negociação da identidade e da diferença.Como resultado, novas identidades são construídas textualmente pela combinação de práticas discursivas, associadas às identidades existentes, cujos limites entre vozes são redesenhados, sendo acrescidas outras vozes ao discurso, ao mesmo tempo, que são apagadas as diferenças entre as diferentes ordens do discurso.

As transformações e as desarticulações da vida social no contexto atual deslocam radicalmente as identidades sociais e confrontam as pessoas com a necessidade de negociar seus relacionamentos com outros em vários níveis, ressalta ainda Fairclough (1997: 298).

Ao enfatizar o lado lingüístico das transformações das relações de estados, de culturas, de classes sociais e de domínios da vida social como sendo, simultaneamente, uma desarticulação e uma rearticulação das práticas discursivas, considera essa mudança como o uso criativo das práticas existentes em novas combinações discursivas.

Compartilha também dessa perspectiva M. Talbot (1998: 152), ao mencionar que a perspectiva crítica comunga a idéia de que o gênero nem é recebido previamente, nem é estático, mas construído ativamente. Alguns estudos sobre a construção do gênero colocam-no como uma performance continuamente em construção, em um processo cujo dinamismo presente lhe assegura a permanente mudança e incompletude.

Ao finalizar este tópico, ressaltamos a possibilidade de estudar a identidade, suas imbricações, conexões e contradições, bem como a identidade social, como uma totalidade complexa que envolve a sociedade, a cultura, a economia e a política, assim como a identidade individual, aquela que constitui a subjetividade e a ação. Mas, sem nos esquecer de que, muitas vezes, os elementos da sociedade encontram-se articulados em uma estrutura relacional hegemônica, que é, por natureza, incompleta e temporária, 
sendo susceptível a qualquer momento de subversão. Nos termos de Gibson e Graham (1996: 112),

O passado está sempre presente em nossas vidas e esse se manifesta em si mesmo de modo paradoxal. Nós vemos por meio de eventos, aprendemos processos, estágios de socialização, os quais não podem ser apagados ou modificados. A nossa subjetividade, entretanto, uma estrutura organizada, nunca cessa de mudar.

Os sujeitos, portanto, resultam de experiências pessoais em diferentes eventos e de processos contínuos de mudanças. Quanto à discussão do modo de agir do sujeito na constituição da identidade, cabe dizer que é difícil acreditar em sujeitos completamente livres ou totalmente assujeitados. É preferível falar de sujeitos ativos que se tornam assujeitados em alguns momentos e que são, em determinados papéis, responsáveis pela constituição da identidade.

Os sujeitos livres, ao optarem por aquilo que desejam, participam ativamente do processo de sua construção. Os assujeitados, todavia, nada mais são que repetidores de discursos pré-existentes, sem ideologias próprias, incapazes de produzir o seu discurso particular. Assim, só o sujeito ativo é o agente particular de seu discurso.

Contrariamente, o sujeito assujeitado torna-se produto do discurso, sendo apenas um repassador de ideologias pré-estabelecidas e seu papel não vai além da reprodução discursiva. Desse modo, é infundada a crença de que existem sujeitos livres que pensam e produzem idéias novas desvinculadas de qualquer influência ideológica e até mesmo de costumes, pois, ao participar de uma sociedade, o sujeito rende-se às formas de pensar, comuns ao grupo social.

Em contraponto, os sujeitos ativos estabelecem uma negociação entre o papel do sujeito assujeitado e o do livre, estabelecendo um meio-termo nessa atuação e, ao fazerem de sua história um modelo sui generis, os indivíduos tornam-se pessoas realmente únicas. Mesmo que cada sujeito agregue variantes sociais e cognitivas construídas com base na história e na reflexão a respeito do mundo e de si mesmo, apresentará marcas exclusivas que se incorporam a sua identidade.

Para Emília Pedro (1997: 157), é a subjetividade, então, com suas múltiplas dimensões, que define a identidade do sujeito, conforme declara: 
Subjetividades não são identidades únicas e simples, mas são multidimensionais. A formação do sujeito toma lugar dentro de uma rede de indicadores que estão associados a uma série de categorias biológica, social e cultural como idade, gênero, etnicidade e classe. De fato, as diferentes dimensões do indivíduo, ambas objetivas e subjetivas, ambas sociais e culturais, parecem ser aspectos irredutíveis de seu/sua identidade.

Ressaltamos ainda que, com a impossibilidade de os sujeitos produzirem discursos conscientes ou inconscientes constantemente, diminui a probabilidade de controlar os discursos proferidos nas diferentes situações de comunicação. Desse modo, por mais reflexivo e cuidadoso que possa ser, o sujeito revela e delineia as características de sua subjetividade e, portanto, de sua identidade, a cada discurso proferido.

A consciência de que o mundo faz parte de seu discurso e de que o sujeito não é apenas um repetidor ou copiador, mas um pensador crítico que considera aspectos estruturais, culturais e contextuais que o cercam, faz emergir o sujeito reflexivo, o qual, ao lidar com ideologias e com estruturas estabilizadas de poder que dominam hegemonicamente os demais sujeitos, altera a constituição de sua identidade.

Ainda em direção à constituição da identidade pelo discurso, contribui mais uma vez Emilia Pedro (1997: 162), ao defender que o ato discursivo é crucial na formação do sujeito porque é no discurso, no texto, junto à impressão recebida por nós dos outros e do mundo, que a modelação de nós mesmos se torna realidade.

A identidade do sujeito, homem ou mulher, não pode ser vista exclusivamente como a propriedade de um ser centrado e com limites predefinidas pelo gênero, que se revela a si próprio na história. Ao contrário, acrescentamos que a identidade é aberta, dominada pela incompletude, multiforme. Tem contornos fugidios e adota traços pessoais, culturais e contextuais que se confundem com a sua própria história. A identidade é, por natureza, híbrida e inconstante.

Ao concluir este tópico, é possível dizer, com Emilia Pedro (1997: 162), que o que nós somos e quem nós somos é o resultado do relacionamento entre o "self e o outro"; conseqüentemente, subjetividade implica intersubjetividade. O papel da língua como um modelo semiótico culturalmente saliente, como um processo da construção e reconstrução do significado, é básico para formar tanto a subjetividade quanto a identidade. 


\section{A tecnologia e a mídia como agentes fragmentadores da identidade da mulher}

Noções ambivalentes e contraditórias sobre o sujeito coexistem na pósmodernidade. A noção de sujeito mistura-se com a de objeto. $\mathrm{O}$ avanço da tecnologia faz com que mulheres e homens interajam com a máquina e que o mundo real se confunda com o virtual. No espaço digital, o sujeito e a subjetividade estabelecem-se na perspectiva dialógica e existem na linguagem e pela linguagem.

No ciberespaço, nasce um indivíduo que não é fruto do determinismo histórico e tampouco é formado por corpo e espírito, tendo deixado de ser um conjunto previsível de estímulos. Cada usuário define a identidade, o gênero, a personalidade por meio de construções discursivas que podem ou não corresponder à realidade física, o que configura uma existência nãocorpórea, mas real. É, enfim, um sujeito tecnológico, midiático e, acima de tudo, discursivo. Sua identidade está em constante movimento e, dadas as suas características efêmeras, é mutante, coletivo e multilinear. É, sobretudo, um sujeito virtual.

Surge um sujeito cuja definição não é feita apenas por critérios ontológicos ou físicos. É construído na linguagem, no contexto e na interação não só com o sujeito-sujeito, mas também com a máquina. Nessa relação entre a construção da subjetividade e a linguagem, é possível antever o papel significativo desempenhado pelos processos midiáticos contemporâneos e, em especial, dos novos agenciamentos da informação, possibilitados pela linguagem da Internet, a qual não foge dessas contradições e traz em si mesma um potencial de subversão da lógica empobrecida da mídia, deixando suas marcas na nova identidade feminina.

A tentativa de assegurar objetividade ao sujeito pelo uso de tecnologias resulta em proposta irreal, que serve apenas para controlar a desumanização profunda dos acontecimentos e do próprio sujeito, que se torna um número, um dado estatístico, uma categoria. Nesse contexto, mesmo parecendo contraditório, podemos observar a liberação e o fortalecimento da identidade da mulher, derivada do enfraquecimento do status quo social e do apagamento ou do desaparecimento de muitas figuras representativas do poder. 
Como exemplo de liberalidade na construção da identidade, podemos citar os bate-papos virtuais (os "chats"), para os quais inexiste a repressão ou qualquer limite social. Nessas circunstâncias, as identidades femininas são liberadas, os comportamentos dos sujeitos são livres das convenções sociais. Nos bate-papos virtuais, as identidades, em sua grande maioria, são falsas e, por essa razão, a ausência de regras aumenta a intimidade na mesma proporção que o descompromisso e a irresponsabilidade ganham espaço nas relações internáuticas.

O anonimato impera nas novas identidades femininas, os nomes desaparecem. Surgem os nicknames. Os nomes virtuais dominam a identidade da mulher. A adoção de nomes de artistas, de seres mitológicos e de heroínas faz com que todos os apelidos sejam incorporados à intimidade virtual. São dezenas de milhares de Madonas, de Medusas, de Olimpos a alimentar a fantasia das novas identidades femininas, negando ou alterando dados que revelam a verdadeira identidade das usuárias. Desse modo, os espaços internáuticos cooperam para a frag mentação e a negação da verdadeira identidade da mulher pós-moderna.

\section{A espacialização no discurso feminino}

Atualmente há na teoria social uma proliferação de referências a noções de espaço. Abundam as metáforas espaciais. É dito freqüentemente que a busca por mais espaço é a meta de todos os que estão na disputa de algum tipo de poder. Metáforas como: "o espaço discursivo tem de ser ocupado"; "as posições da fala têm de ser marcadas, situadas ou definidas"; "limites devem ser ultrapassados, transgredidos" são comuns nos discursos femininos.

Associadas à análise marxista, derivam inúmeras metáforas espaciais. Termos metafóricos como "colonização", "penetração", "cerne e periferia" e "terrenos de luta" são comuns no discurso marxista. A teoria estruturalista, como a marxista, representa um espaço constituído por ou em relação com "identidade" ou "forma”. Diz Graham e Gibson que, enquanto a teoria pós-estruturalista está preocupada com a problematização da fixação de identidade e com o traçado do espaço de realização das múltiplas identidades, a teoria marxista focaliza o espaço destinado ao modo de produção ou, mais particularmente, ao capitalismo. 
Essas tentativas metafóricas invocam os espaços naturalizados, nãosociais, absolutos, com o intuito de contextualizar e de desuniversalizar os espaços sociais e as atitudes de fala. Mas é esquecido que essa mesma concepção é produzida socialmente em contexto histórico específico e, ao multiplicarem metáforas espaciais, os teóricos sociais reproduzem uma visão de espaço politicamente carregada com implicações históricas que, ao mesmo tempo, são modernas.

Na disputa pelo espaço, conforme Wilson (1991) e Saegert (1980), às mulheres cabe o espaço periférico enquanto aos homens tocam os espaços mais centrais, as zonas industriais e as áreas comerciais. A figura feminina é vista como um espaço vazio. Nas práticas discursivas comerciais, as mulheres devem ser preenchidas pelo consumo, posicionando-se no discurso apenas como compradoras. Como espaços de reprodução biológica, os corpos femininos são representados como vazios, necessitando de cuidados enquanto aguardam o preenchimento pela maternidade. Nas relações afetivas, a mulher deve ser guardada no interior da casa e o seu papel é o de guardiã passiva do bem-estar masculino.

Desse modo, uma interpretação de espaço, claramente definida, contribui para uma política de identidade. Daí porque o interesse pelo conceito de espaço no discurso feminino. Segundo Wilson (1991), pesquisas geográficas comportamentais de estrutura urbana têm demonstrado imagens de mulheres habitando determinados espaços da cidade que marcam bem os padrões de gênero, assim como as redes sociais envolvidas no espaço doméstico, no espaço de vizinhança e no espaço de comércio local.

\section{O discurso do corpo na auto-realização identitária}

No presente, o corpo tem sido altamente valorizado como um componente discursivo que define e compõe a identidade da mulher. Acredita Foucault que o corpo do homem não poderia ter existido como fundamento para o discurso antes da mudança do quadro epistemológico do conhecimento no século XIX. Para ele, o homem é uma invenção de data recente e, talvez, já muito próximo de seu fim.

O corpo é um veículo. Habitá-lo, às vezes, é encarado como privilégio, noutras como uma "pena imposta", declara Giddens (2000). O corpo é a fonte de bem-estar e de prazer, mas também pode ser o invólucro de 
doenças e de pressões. Destaca ainda o eminente sociólogo que o corpo manifesta vários aspectos do self e da auto-identidade. A aparência corporal passa pelo modo de vestir, pela escolha dos acessórios e também pela postura, que, como a aparência, é trabalhada no cotidiano. Passa também pela sensualidade, que envolve prazer e dor, e pelos regimes aos quais o corpo é submetido em busca de perfeição.

A aparência e a postura não são adquiridas, mas construídas pela mulher, dependem do meio cultural a que estão agregadas. Cuidar do corpo significa ouvi-lo constantemente tanto para buscar boa saúde como para identificar o que está errado. O corpo tem o poder de ajudar a manter a boa aparência do sujeito e, por conseqüência, a sua satisfação. Mas nem sempre a mulher consegue controlar o seu corpo, sendo comuns mulheres, no intuito de preservá-lo, desenvolver doenças como a anorexia nervosa ou a bulimia, versões extremas das preocupações com o corpo que podem contribuir positivamente para aperfeiçoar a identidade ou negativamente para distanciá-la dos ideais almejados.

Bourdieu (1994: 3) Sugere que a linguagem seja considerada como uma dimensão corporal em que a relação global das pessoas com o mundo social se expressa. Ele chama atenção ainda para o estilo articulatório das classes populares, cuja relação da pessoa com o próprio corpo é inseparável. É esse mesmo estilo que denuncia excessos de maneirismos, feminismos ou virilidade exagerada no modo de falar. A união das diversas características do discurso e do comportamento constrói uma versão particular do "eu" e constitui o ethos, manifestado pelo corpo inteiro, não só pela voz.

O conhecimento feminino do corpo, construído pelos movimentos ativistas das mulheres que lutam contra a violação, é explorado por Gibson e Graham (1996: 116.). A linguagem feminista situa a violação como uma realidade da vida das mulheres e constrói o seu discurso com base na habilidade assumida do violador (masculino) para subjugar fisicamente o seu alvo. Para Sharon Marcus (1992: 387), uma ativista feminista, autora de um dos principais escritos sobre a violação, defende que um dos propósitos dos projetos de antiviolação é criar um conhecimento público profundo a respeito do tema, cujo intuito seja o de fortalecer a política feminista.

Marcus argumenta que o custo do sucesso feminista tem sido a aceitação generalizada de uma linguagem de violação que solicita às mulheres que se posicionem como postas em perigo, como violáveis e medrosas, 
postura que convida os homens a posicionarem-se como legitimamente violentos e com direito aos serviços sexuais das mulheres. No dizer de Marcus (1992: 398), essa linguagem estrutura ações físicas e respostas, assim como palavras e formas, como, por exemplo, os pretensos sentimentos de força do violador e o conhecido sentimento de paralisia das mulheres quando ameaçadas com violação.

O escrito de Marcus trata dos corpos das mulheres como um espaço vazio que espera ser invadido, preenchido. Vejamos o que Marcus (1992: 398) diz sobre o corpo da mulher.

O escrito da violação descreve os corpos femininos como vulneráveis, violáveis, penetráveis e feridos; metáforas de violação como "trespasse e invasão" retêm esta definição intacta. O corolário psicológico desta metáfora de propriedade caracteriza a sexualidade feminina como um espaço interior, e uma política antiviolação como um meio para salvaguardar este espaço interior do contacto com qualquer coisa exterior a ele.

As reflexões feministas sobre o corpo nas esferas psicológica e social não desejam purgar esse discurso; ao contrário, elas particularmente foram responsáveis por conceber o corpo como foco relevante de tais discursos, com importantes implicações teóricas e efeitos sociais. Mas, sem dúvida, o realinhamento do conhecimento do corpo, abre novas perspectivas para os estudos da formação identitária da mulher.

\section{A identidade da mulher diante das transformações da sexualidade}

A partir do século XVIII e, especialmente, do século XIX, o discurso sobre sexo, antes restrito à Igreja, dispersa-se em diferentes áreas do conhecimento. Além da medicina, da biologia e da psiquiatria, outras áreas, como a demografia e a política, passam a se preocupar com o sexo, construindo novos conceitos e imagens sobre a mulher que são estendidos ao gênero feminino como um todo.

Frente às questões sexuais do passado, a repressão e a anulação da mulher foram substituídas pela liberação e pela independência dos dias atuais. Assim, a mulher contemporânea, com base em novas redes de poder, impõe-se na sociedade em diferentes áreas, inclusive na sexual, tendo 
espaço para preferências e vontade em assuntos que antes não podiam sequer ser mencionados em discurso privado, quanto mais ser objeto de discurso público.

A mulher atual define sexo, em sua identidade, como algo que deve ser prazeroso. A respeito de poder e prazer, parece ser relevante lembrar as palavras de Foucault (1985: 45), ao afirmar que o relacionamento sexual deve haver:

Prazer em exercer um poder que questiona, fiscaliza, espreita, espia, investiga, apalpa, revela; prazer de escapar a esse poder. Poder que se deixa invadir pelo prazer que persegue-poder que afirma no prazer de mostrar-se, de escandalizar, de resistir.

A sexualidade, nas palavras de Michel Foucault (1985: 45), é discursiva, fazendo sentido apenas quando inscrita na linguagem e no discurso em processo em que o saber e o poder se tornam inseparáveis. Ao tratar sexo como construção semântica, dependente de representações específicas, Foucault defende que o estudo da sexualidade deve centrar-se nos discursos do desejo, explorando as palavras, a linguagem e os símbolos.

As modernas tecnologias, como a Internet, legitimam a citação de Foucault ao permitirem aos navegadores uma atividade sexual de natureza confessional, que os autoriza a contar em sigilo experiências sexuais, incluindo a possibilidade de ver e trocar imagens de sexo. Nesse contexto, instalam-se novas práticas sexuais por meio virtual e, diferentemente de outras práticas que envolvem a sexualidade, os usuários dos meios virtuais não carecem mais de ocultar-se; não há quem os possa vigiar ou punir por falarem ou por praticarem sexo virtual. $O$ prazer sexual, aliado à possibilidade discursiva de interagir com o outro, faz com que, no que toca à identidade da mulher, haja uma libertação gradual na área sexual e uma expansão dos seus limites, transformando conceitos e formas de ação na esfera sexual.

\section{A sexualidade como construção cultural}

A diferença sexual, em tese, depende do fato de alguém ter nascido moça ou rapaz. Tal acontecimento não depende de escolhas. É puro casuísmo, assim como a cor da pele, dos olhos, do cabelo, da família, da nacionalidade e do sexo. Todos esses dados constituem variáveis não-controláveis. 
A ninguém é perguntado antes do nascimento que sexo ou que nacionalidade ou família gostaria de ter. Mas, depois que alguém nasce, começa um longo processo social de construção de identidade, cujos efeitos sobre cada indivíduo são imprevisíveis. Mesmo que os elementos culturais referentes a sexo ou à nacionalidade não sejam inatos, a sua influência na construção identitária começa cedo na vida do sujeito.

Indivíduos do sexo feminino podem aprender formas de comportamentos sociais menos ortodoxas desde que o contexto sociocultural thes permita aprender. Encontrar jovens mulheres empunhando fuzis em Israel, por exemplo, é um fato corriqueiro, pois elas convivem socialmente com o terrorismo e a guerra desde cedo. Repentinamente, premidas pelas circunstâncias, outras mulheres, motivadas por separação, divórcio ou viuvez, assumem papéis marcadamente masculinos e atestam com sucesso a possibilidade de novas construções identitárias na esfera dos sexos.

Em diferentes situações, uma das maiores queixas de mulheres sozinhas é a dificuldade de lidar com o dinheiro, com as contas e com outras questões burocráticas, geralmente tratadas pelos homens. Mas, após algum tempo, essas mulheres assumem diferentes papéis e exercem com desembaraço as novas funções qualificadas como masculinas, fato que comprova serem esses papéis passíveis de aprendizado. De igual modo, homens que, por separação ou morte do cônjuge, recebem a guarda dos filhos e a gerência do lar, aprendem, mesmo com alguma relutância, as atribuições femininas.

Ademais, a sociedade está acostumada ao discurso de que as diferenças culturais podem trazer dificuldades nas relações sociais e até mesmo o confronto e o enfrentamento. No que toca aos gêneros, se os sexos masculino e feminino forem considerados como duas culturas diferentes que coexistem em um mesmo contexto, constataremos que nem sempre essas diferenças têm sido consideradas. As distâncias culturais que envolvem os dois sexos são visíveis no modo de ser, de falar, de pensar, de sentir, entretanto nenhuma dessas culturas vê essas diferenças na outra. A respeito das características das culturas masculinas e femininas, Hofstede (1991: 106) declara:

Quando os homens estão juntos, a cultura masculina tem tendência a predominar, e, no inverso, a cultura feminina domina quando as mulheres estão reunidas. Dar a estas diferenças o nome de "culturas" acentua a sua natureza profunda a emocional. A cultura feminina é albeia à 
maior parte dos homens e o inverso também é verdadeiro. O contato com uma cultura estranha desencadeia muitas vezes um choque cultura, que constitui uma reação visceral irracional. As outras culturas parecem-nos por vezes à primeira vista ridículas, inquietantes ou equivocadas. Este tipo de sensação pode existir entre os sexos no interior de uma mesma sociedade. Em quase todas as sociedades, os homens dominam a vida política, a vida social e o mundo dos negócios.

Por essa razão, determinados comportamentos discursivos comuns à cultura masculina são proibidos à feminina e vice-versa. No universo das mulheres, pela construção social a que está sujeita a linguagem, geralmente são interditadas certas palavras relativas ao sexo e às partes sexuais. Certos tabus cristalizados no discurso são estendidos às questões sexuais em geral, mas de modo muito mais rigoroso ao gênero feminino e à sua sexualidade, que, por sua suposta natureza frágil e dependente, tem sido alvo freqüente da repressão e dos cuidados morais da sociedade em geral. Certas práticas discursivas masculinas que abrigam palavrões e obscenidades em discursos femininos são objetos de censura.

Desse modo, a sociedade constrói, então, não só uma identidade social, mas também uma sexual, que pode ser reforçada em qualquer domínio da vida compartilhada, como nas relações afetivas, familiares, educacionais e profissionais. Assim, no perfil de cada grupo de profissões em cada país, há limites e definições culturais e também sexuais. A profissão de professor para crianças no Brasil, por exemplo, é essencialmente uma tarefa feminina.

Nessa divisão de papéis, cabe às mulheres a responsabilidade da educação infantil, sendo rara a presença de representantes do gênero masculino nessa função educativa. O ensino na escola primária e os afazeres do lar sempre foram aceitos pela sociedade brasileira como uma ocupação tipicamente feminina.Como a educação das crianças está comumente entregue às mulheres, acredita-se que o seu papel na escola tenha sido uma extensão dessa responsabilidade do lar.

Em contrapartida, no ensino superior e médio aumenta consideravelmente o número de professores homens. A educação nos demais graus deixa de ser privilégio das mulheres. Mesmo assim, o número de professoras ainda é muito maior e expressivo. Há profissões, entretanto, que parecem prescindir do gênero feminino, como é o caso da de banqueiros, uma ocupação tipicamente masculina. Se a mulher, em uma dada sociedade, ocupar a posição de banqueira, certamente, o banco ou foi herdado, ou recebido em partilha de divórcio. 
Como uma função marcadamente masculina, aos homens, de modo geral, cabe o gerenciamento do dinheiro tanto na vida privada como na pública. Novamente ocorre a extensão de papéis sociais atribuídos ao homem: administração das finanças, dos pagamentos, das contas e das economias. David Barton e Mary Hamilton (1991) constataram, em pesquisa em comunidade inglesa sobre os papéis do casal nos eventos de letramento, que as atividades bancárias, em sua maioria, eram de responsabilidade masculina. Entretanto, pertenciam ao gênero feminino os eventos sociais, como enviar e escrever cartas aos familiares, cartões natalícios e fúnebres.

É verdade também que os feitos masculinos, no decorrer da história, parecem reforçar o poder e o sentido de competição entre os homens. Do mesmo modo, os cuidados e a proteção feminina, dedicados à família, fortalecem a sua natureza generosa e envolvente, preocupada com o bemestar familiar e com as relações sadias do lar. A esse respeito, assim se pronuncia Geert Hofstede (1996: 101):

Encontramos uma tendência comum na maior parte das sociedades, modernas ou tradicionais, no que diz respeito à distribuição dos papéis sociais segundo o sexo Os homens devem estar ligados a atividades exteriores ao lar: à caça e à guerra nas sociedades tradicionais e o equivalente, traduzido em termos econômicos nas nossas sociedades modernas. Resumindo, os homens devem ser firmes, competitivos e duros. As mulheres devem tratar do lar e das crianças, dos outros e em geral: devem adotar os papéis "ternos". A origem desta distribuição não é difícil de imaginar: as mulheres davam à luz suas crianças, alimentavam-nas e eram portanto obrigadas a permanecer perto delas durante algum tempo. Os homens tinham mais liberdade de movimento, sempre que não tinham de proteger as mulheres e os filhos de ataques exteriores.

De fato, certo determinismo histórico-cultural constrói os papéis sexuais mesmo quando desejam opor resistência. Os homens, livres para irem e virem em qualquer direção, tendem a dominar a vida social fora do lar. No interior, a repartição das atribuições pode ser variada, mas, comumente, é legado das mulheres o cuidado do lar. Por essa razão, são tão difíceis e lentas as mudanças sociais referentes à identidade das mulheres, pois cada alteração deve desconstruir processos históricos de séculos de preconceitos e de crenças, solidamente estratificados no seio da sociedade.

Mas, de qualquer modo, o papel do pai e da mãe ou de outros membros da família na construção social da identidade do sujeito pode provocar impactos profundos não só na programação mental, como também na desconstrução de conceitos e de práticas sociais de comportamento. Quer o 
sujeito seja mulher, quer seja homem, os pais são os primeiros responsáveis pela definição de modelos identitários, assim como pela reprodução cultural de valores e de princípios morais e éticos e também sexuais de cada sujeito.

Hofstede (1991: 103) diferencia as sociedades em termos de suas dimensões sexuais, definindo-as da seguinte forma:

Serão ditas masculinas as sociedades em que os papéis são nitidamente diferenciados (o homem deve ser forte, impor-se e interessar-se pelo sucesso material, enquanto a mulher deve ser mais modesta, terna e preocupada com a qualidade de vida); são femininas aquelas sociedades em que os papéis sociais dos sexos se sobrepõem (tanto homens e mulheres devem ser modestos, ternos e preocupados com a qualidade de vida).

De acordo com os estudos sobre índice de sexualidade predominante nas nações, relatados por Geert Hofstede (1991), há países preponderantemente masculinos em seus valores, como é o caso do Japão e da Áustria, onde homens e mulheres têm valores "duros" (masculinos). Os valores do índice de sexualidade foram calculados por país e também, separadamente, para homens e para mulheres em cada país. Os resultados mostram que os valores dos homens e das mulheres se tornam mais masculinos à medida que sobe o índice de masculinidade do país. Em países mais femininos, como a Suécia e a Noruega, não existem diferenças entre os resultados dos dois sexos, que exprimem os mesmos valores de ternura e de generosidade. A seguir, no próximo item, será examinada a constituição do gênero segundo a perspectiva da família.

\section{A família como agente construtor da identidade feminina}

Sem dúvida, é na família que a identidade da mulher e do homem recebe as primeiras programações culturais, pois é nela que se constroem diversos tipos de relações, de comportamentos e de condicionamentos culturais e sociais. A divisão dos papéis entre o casal para a educação dos filhos reflete os valores e as crenças da instituição familiar. Em geral, a esposa cuida do funcionamento do lar enquanto o marido trata da obtenção dos recursos materiais e financeiros para a sua manutenção.

Naturalmente, cada família tem regras e valores próprios. Segundo Giddens (2000), as famílias desenvolvem um currículo oculto de ensina- 
mentos. De qualquer modo, é comum na pedagogia familiar do Ocidente que as meninas, inda no berçário, ganhem brinquinhos e vestes cor-derosa e que recebam um pequeno laço de fita nos cabelos logo após o primeiro banho. Assim, daquele momento em diante, instala-se na vida daquela pequena mulher o início do aprendizado dos rituais de beleza que deverá fazer parte de sua identidade feminina durante toda a sua vida.

Para os meninos, entretanto, são outras as regras. Devem aprender desde muito pequenos a não chorar, a serem duros com relação aos seus sentimentos. Aprendem, além disso, a revidar aos ataques externos e também são incentivados a tentativas sexuais com o sexo oposto. Em suma, do mesmo modo que as mães trabalham a vaidade em suas meninas, os pais desenvolvem a violência e a sexualidade nos meninos.

Sobre a formação dada pela cultura familiar Hofstede (1991: 109) acrescenta:

Há países onde a norma é um pai dominante e duro e uma mãe submissa; esta, embora também seja dura, constitui ao mesmo tempo o refúgio para a consolação e a ternura. O termo universalmente conbecido de machismo" aplica-se exatamente ao comportamento esperado dos homens nos países da América Latina (...). É menos conbecido o termo aplicado as mulheres: o marianismo, uma mistura de santidade, de submissão e de frigidez sexual.

O estudo que identifica graus de masculinidade nas sociedades demonstra principalmente que homens e mulheres têm valores mais duros nos países classificados como masculinos e mais suaves nos países femininos. Nos países femininos, as jovens mulheres aprendem a ser ambiciosas e competitivas, embora a ambição delas esteja direcionada ao sucesso dos irmãos, do marido ou dos filhos, raramente a si próprias. Em relação aos países considerados femininos, os jovens, de ambos os sexos, aprendem a serem modestos, a ter comportamentos assertivos e a buscar a excelência, a qual deve ser guardada para si mesmos, não devendo ser exibida.

Há outros países em que o modelo paterno deve ser o exemplo a ser seguido. A figura do pai ocupa-se principalmente dos fatos, enquanto a mãe cuida dos sentimentos. O modelo resultante é o de que os rapazes devem afirmar-se por meio de ações claras de liderança. Quando agredidos, devem revidar e, sobretudo, não chorar. As jovens são estimuladas a agradar o sexo masculino. Têm o direito de chorar, mas não o de bater. 
No que diz respeito á construção da identidade, qualquer modelo familiar estabelecido serve aos propósitos deste artigo, que é o de mostrar que desde muito cedo as identidades de mulheres e de homens são construídas no contexto social. A identidade de gênero, em suma, é produto de comportamentos sociais aprendidos com a família e com outras instituições sociais como a escola.

Nesse sentido, contribui Emília Pedro (1997: 160) ao dizer que a compreensão da formação da identidade deve-se a

Uma tarefa realizada pelo sujeito juntamente com outros sujeitos, tais como pais, professores, amigos e parentes. Identidade, então, também implica trabalbo, exatamente como o trabalho artístico é produto de práticas criativas. Mas de modo diferente da maioria dos trabalhos de arte, a identidade nunca está completa.

Nas relações familiares, as mudanças identitárias têm sido estimuladas pela troca, redução ou expansão de papéis. A família tradicional (com pais, irmãos, avós, tios e primos) tende a alterar cada vez mais os seus contornos e muitas dessas famílias só existem em antigos retratos. Em conseqüência, as novas relações parentais estão redesenhando uma nova identidade para a mulher e também para os membros das novas famílias.

Surgem agora os irmãos do primeiro, do segundo e até mesmo do terceiro ou quarto casamento. Há a mãe verdadeira e as mães emprestadas dos outros casamentos. Surgem várias avós e avôs. Sem falar das uniões de casais do mesmo sexo nas quais, se decidirem pela adoção de uma criança, uma variante de composição familiar, haverá ou dois pais, ou duas mães. A respeito da estrutura familiar, ainda acrescenta Hofstede (1996: 109):

Numa sociedade coletivista onde o modelo é a família alargada, o modelo de autoridade pode ser o avô, constituindo o pai o modelo de obediência. Nas sociedades ultra-individualistas abundam famílias monoparentais nas quais os modelos de papéis estão incompletos ou são assumidos por pessoas externas. Esta tipologia permite realçar a importância da repartição dos papéis no seio da família numa sociedade no que concerne aos valores que são transmitidos de em geração em geração.

Vale dizer ainda que os valores e os comportamentos ligados ao gênero são programados sutilmente desde a mais tenra idade. Segundo Hofstede (1996), uma pesquisa comparativa dos comportamentos das mães e dos seus filhos, realizado por Otaki e outros (1986: 108), que estudou crianças 
japonesas entre três e quatro meses, no Japão e nos Estados Unidos, mostrou que os bebês-rapazes japoneses eram nitidamente mais barulhentos que as meninas, enquanto se passava o inverso com os bebês americanos.

É improvável que as diferenças identificadas por Otaki entre os dois sexos sejam inatas. Elas devem ter origem no condicionamento da educação dada à criança pela mãe, diferindo segundo o sexo da criança e a nacionalidade da mãe, a qual pode incentivar atividades mais barulhentas ou mais calmas de seu filho, de acordo com as expectativas da sociedade em que vive, relativamente ao que é esperado do comportamento das moças e dos rapazes.

Nas culturas masculinas, as crianças desde cedo aprendem a apreciar e a admirar a força. Os heróis de histórias de ficção são figuras extremamente fortes. Todos eles com características de poder fora da média da normalidade terrena e humana. Nas culturas femininas, as crianças aprendem a gostar do oprimido, um tipo de anti-herói, que, apesar das características contrárias e adversas, consegue vencer o seu opositor.

Gibson e Graham (1996: 30) lembram-nos também de que, no princípio dos anos 70, muitas pessoas pensaram ser paranóicos os argumentos feministas da existência de um regime de sexismo ou domínio masculino. Esses argumentos mostravam que a descrição feminista da dominação masculina não era tão visível e não se manifestava plenamente no comportamento dos homens, como de fato as feministas levavam freqüentemente a crer.

Tal fato não significava que não existissem práticas e condições de dominação masculina, mas que essas práticas e condições eram muito mais sutis do que declaradas, apenas visíveis em alguns lugares. Revelar a sua existência não era tarefa simples. Daí a razão de ter sido requerido às feministas um discurso popular cujo objeto constituísse verdadeira luta política no sentido de revelar as práticas de dominação do sexo masculino.

Por fim, vale a pena enfatizar mais uma vez que cabe à família, portanto, grande parte da tarefa de construir a identidade feminina. É pertinente dizer, com Simone de Beauvoir, que "não se nasce uma mulher". A mulher é feita, ela é uma espécie de mundo em construção e mudança. A sua identidade reflete as cores da sociedade contemporânea com suas qualidades, erros, falhas e fragilidades. 


\section{A questão identitária e o ensino}

Ao refletirmos sobre o ensino e a construção da identidade feminina, devemos inicialmente prestar atenção na questão curricular, uma vez que a escolha de disciplinas traduz o papel da sociedade e dos seus valores ideológicos na construção da identidade da mulher. Vale lembrar, como exemplo, dos currículos voltados à formação feminina nas Escolas Normais brasileiras, lugar em que as futuras professoras aprendiam desde puericultura até canto orfeônico, além de noções preliminares de economia doméstica. Entretanto, não aprendiam física, nem biologia, nem química. O discurso da época para os cursos de magistério era de que a jovem que fizesse tal curso, ao mesmo tempo, que se prepararia para se casar, poderia também, quem sabe, trabalhar fora meio turno, preferencialmente, o da tarde.

A diferença entre os dois sexos torna-se evidente na sala de aula. Nas culturas classificadas como masculinas, os alunos tentam destacar-se do grupo e entram claramente em competição uns com os outros; já em culturas nitidamente femininas, os alunos não devem parecer muito ambiciosos e a solidariedade entre alunos constitui regra tácita.

O distanciamento entre essas duas culturas é visível também nas escolhas curriculares. Os dados de diversos países relativamente à divisão dos sexos em determinadas áreas de ensino como direito, ciências sociais, ensino, engenharia e agricultura permitiu identificar um tipo de discriminação nos cursos superiores. Há cursos como Direito, por exemplo, cujo índice de homens tende sempre a ser maior do que o de mulheres, e os cursos direcionados ao ensino, em que o número de homens é inexpressivo.

Nos países com valores masculinos, a escolha profissional é motivada, sobretudo, pelas oportunidades de carreira que oferece, enquanto, em culturas femininas, o interesse do estudante por determinado domínio desempenha papel decisivo para a sua escolha. $\mathrm{O}$ insucesso escolar constitui desastre em culturas masculinas como a japonesa e a alemã, países cujos índices de suicídio de estudantes são alarmantes. Nas culturas femininas, o insucesso escolar é de menor importância. É interessante observar também que os alunos avaliam os professores de modo diferente nas duas culturas. O brilho acadêmico é indispensável aos professores de culturas masculinas, enquanto a simpatia do professor é o fator mais apreciado nas culturas femininas. 
Expressivo número de pesquisas demonstra essas diferenças no ensino. As investigações de Cornes (1994: 105) sobre letramento ratificam a crença de que as necessidades de letramento do homem e da mulher não são as mesmas. Essa idéia enraíza-se no fato de que, enquanto o sexo é biologicamente determinado, o gênero é socialmente construído em cada sociedade. "Características femininas" não são biologicamente determinadas e não estão universalmente presentes na espécie humana, antes, essas características relacionam-se intimamente com os papéis particulares, os quais as mulheres têm assumido.

Com base nesse ponto de vista, é possível explorar a idéia de que os papéis masculinos e femininos podem alimentar tipos ou necessidades diferentes de letramento, na intenção de preencher papéis específicos dos gêneros e de superar os estereótipos atrelados aos papéis.

Jean-Jacques Rousseau, segundo Cornes (1994: 105), a respeito da educação feminina, delineou o programa de ensino a seguir:

A completa educação das mulheres deve ser relativa aos homens, para agradá-los, para serem úteis a eles, para que se façam amadas e honradas por eles, para educá-los quando jovens, para cuidar deles quando crescidos, para consolá-los e para tornar-lhes a vida doce e agradável. Estas são as obrigações das mulheres em todos os tempos e é assim que elas deveriam ser ensinadas desde a infância.

Ao delegar às mulheres o cuidado dos filhos e do lar, a sociedade atual reforça inconscientemente a filosofia rousseauriana, sendo essa uma das razões de elas não apresentarem muitas necessidades de letramento, haja vista que em muitas sociedades, ainda hoje, as mulheres são proibidas de ler e escrever. Daí porque até recentemente o número de homens ser mais escolarizado do que as mulheres.

Como pôde ser visto, a educação de fato contribui para a legitimação de características que manifestam e aprofundam as diferenças entre os dois sexos, fazendo com que a identidade das mulheres desde cedo seja trabalhada e construída em torno de valores culturais específicos de cada sociedade. Desse modo, são reiterados os valores femininos de cada cultura, o que faz com que a identidade da mulher seja um reflexo das crenças, valores e costume de cada grupo social. 


\section{O trabalho como força estruturante da nova identidade feminina}

A divisão do trabalho em todas as sociedades humanas depende mais das condições culturais e menos das condições sexuais. Homens e mulheres distanciam-se em extremo não apenas por causa das diferenças físicas e biológicas, mas também pelos papéis desempenhados nos eventos sociais. As diferenças, apesar de marcarem a separação entre os sexos, não estão relacionadas diretamente com a atividade ou com o trabalho desenvolvido.

Em geral, os homens são maiores e mais fortes. As mulheres, conforme o senso comum, têm habilidade manual e intuição mais apurada que lhes permitem lidar com situações cujos envolvimentos sociais e emocionais sejam maiores. Contudo, mesmo com diferenças e atributos tão específicos, não são esses que determinam a ocupação dos sexos no mercado de trabalho, mas as práticas sociais vigentes que, consoante a ocupação de homens e de mulheres, refletem a história da humanidade.

As sociedades identificam determinados comportamentos como mais adequados a um sexo do que ao outro. Estudos de sociedades letradas e iletradas que investigaram sociedades desprovidas de escrita e, relativamente isoladas, insistem na infinita variedade de papéis consignados a cada sexo. Em determinadas tribos indígenas, por exemplo, é papel do homem caçar, seguir rastros e pistas de animais e de pessoas. Cabe também a ele descansar na rede no período de gravidez de sua companheira e contar histórias para a tribo ao pé da fogueira, papéis tidos como exclusivamente femininos em outras culturas.

Os comportamentos considerados "masculinos" ou "femininos", como já foi visto, têm mudado com o passar do tempo tanto nas sociedades tradicionais, como nas pós-modernas. Isso ficou visível quando consideramos a distribuição do gênero masculino e feminino em certas profissões. Na ex-União Soviética, a profissão de médico era preenchida por mulheres, assim como a de dentista na Bélgica ou a de comerciantes na África Ocidental, mas, ao contrário, as funções de secretárias eram exercidas, em sua maioria, por homens no Paquistão. Na Holanda, do mesmo modo, há elevada proporção de enfermeiros homens e no Japão não existem praticamente mulheres na função de dirigentes de empresas, enquanto nas Filipinas e na Tailândia isso é bastante comum. Assim, nas atividades profissionais, 
um homem pode comportar-se de forma feminina e uma mulher de forma masculina.

Quando as mulheres comęaram a ingressar no mercado de trabalho, as relações entre os dois sexos entraram em processo de mudança. Ela, ao conquistar salários, ingressa também no clube dos capitalistas, que, usualmente, era privilégio masculino. Começa, portanto, a luta pelo poder que excede a questão de gênero. O homem, neste momento, deve lutar para se manter em seu cargo, para não perdê-lo a outros concorrentes homens e, também, agora, às mulheres.

O homem, por essas razões, está em estado de choque, não sabe como lidar com essa nova identidade da mulher que está em forte processo de mudança. Ouvi o depoimento de um marido cuja mulher é empresária de sucesso: "Lugar de mulher é em casa, bem perfumada e bonita, administrando o lar. O trabalbo pesado é para o marido".

Esse discurso exibe a construção cultural de que a função da mulher é de adorno e sua exclusiva finalidade é o deleite masculino. O homem está habituado a estar no controle da situação. Com a mulher fora de casa, as relações interpessoais do casal estão sujeitas a outras formas de interferência, como os horários de trabalho, as agendas, os compromissos extras, podendo, em alguns empregos ocorrer até mesmo viagens. Tudo isso deixa o homem contemporâneo inseguro e, ao mesmo tempo, que ele não deseja se casar com uma Cinderela que não tenha uma carreira, lida com dificuldades com as responsabilidades profissionais da mulher.

Assim, no que toca ao trabalho, uma nova visão discursiva instala-se. As mudanças profissionais reivindicadas pelas mulheres no novo mercado emergem com valores modificados, centrados em promissoras propostas que podem desestabilizar a hegemonia masculina no mundo profissional. A intervenção feminina nesses mercados levanta problemas para a liderança masculina, principalmente, nas economias capitalistas. Então, é possível que essa intervenção marque o início de um discurso inovador do gênero feminino no mercado de trabalho, definindo uma nova identidade profissional para as mulheres, e que a competitividade seja uma das novas características identitárias nessa disputa por mais espaço no campo profissional.

Na constituição de uma autêntica identidade profissional para o gênero feminino, a palavra de ordem é êxito. A mulher contemporânea tem de ser bem-sucedida nas suas atividades profissionais, considerando que tudo na disputa do mercado de trabalho é mais difícil para a mulher do que para 
o homem, desde a obtenção de emprego até galgar posições hierárquicas superiores que dão destaque profissional. $\mathrm{O}$ discurso do gênero masculino tem sido pródigo em negativar a auto-estima da mulher no que concerne a sua competência para se desincumbir de tarefas quotidianas.

O discurso naturalizado de que toda a mulher é menos competente do que o homem para as tarefas mais triviais tem sido lugar comum. Ao dirigir um automóvel, por exemplo, as mulheres estão sujeitas a críticas freqüentes e, embora as estatísticas comprovem que as mulheres provoquem e sofram menos acidentes do que os homens, eles as diminuem constantemente nessa atividade. Basta um deslize para a mulher ser chamada de barbeira e ouvir assertivas como: "Sópodia ser mulher na direção". No campo profissional, se a mulher, depois de muito esforço pessoal, for promovida, a primeira coisa que dizem é: "Como será que ela conseguiu esta promoção? O que será que ela fez para obtê-la? Mas, quando um homem é promovido, o discurso muda completamente: "Como ele é competente" ou "Esse cara vai longe, ele promete".

Ainda quanto aos ataques masculinos à identidade feminina, é comum encontrar em língua portuguesa tanto no Brasil como em Portugal piadas e provérbios que ilustram o descaso e o desrespeito pessoal e profissional a que as mulheres estão sujeitas. Além de piadas, há também estereótipos populares que, de alguma forma, destroem a identidade da mulher. O estereótipo de que toda a loira é burra é tão natural no discurso que a TV, tanto portuguesa como brasileira, faz dela motivo de piadas. No Brasil, costumam dizer que chamar mulher loira de "loira burra" não é adjetivar, é usar pleonasmo vicioso.

Mesmo considerando o sexo feminino menos capaz, para algumas atividades profissionais, existem determinados homens que exploram as esposas ou companheiras em certos trabalhos, pois, ao estabelecerem parcerias de trabalho com a mulher, agem como senhores feudais, apropriando-se de todo o rendimento produzido por ela. Um exemplo para esse caso é o de esposas que participam do trabalho, da mão-de-obra de negócios geridos pelo marido. Elas tomam parte ativa em todas as etapas do trabalho, mas não têm acesso aos lucros. Toda a receita pertence ao seu senhorio, dono do seu corpo, do seu tempo e também de seu trabalho. Em verdade, é uma exploração trabalhista encoberta pelos laços do matrimônio ou pelas relações afetivas. 
Nesses casos, todo o gerenciamento financeiro é feito pelo marido, que elege as prioridades para aplicar ou gastar o dinheiro. Há muitos casais nessas condições: ela, muitas vezes, não desfruta do estritamente necessário para uma sobrevivência digna, enquanto ele, o marido, usufrui de carros, de motos e muitas vezes até de outros prazeres estritamente masculinos. Nessas condições, ao usar o trabalho da esposa ou companheira, o marido exime-se de contratar empregados e de cumprir obrigações trabalhistas tais como férias, descanso remunerado entre outros.

Mas, para equilibrar esse quadro contrário ao gênero feminino, as mulheres, gradualmente, estão se tornando mais politizadas, conscientes de seu valor na força do trabalho e também nas relações afetivas. Muitas, já ao se casarem, exigem um contrato pré-nupcial que lhes garanta certa segurança nas questões de separação e divórcio, temendo as perdas futuras, pois, ao separar-se, a mulher depara-se com a perda não só de sua identidade de mulher respeitável e séria (garantida, segundo a nossa cultura, pelo casamento), mas também com a perda da auto-estima, tornandose, em todos os sentidos, literalmente, mais pobre.

Em muitas comunidades, mulheres nessas circunstâncias não desfrutam de respeito social, sendo olhadas com certa desconfiança. Geralmente, as mulheres separadas ou divorciadas perdem muito nas relações sociais. Os casais de amigos afastam-se. Mulher sozinha não é bem-vinda em reuniões de casais. De certo modo, "as amigas" sentem-se ameaçadas. Diante de tais situações, os relacionamentos tendem cada vez mais a ser alvos de cuidadosas negociações sob a vigilância de um feminismo crescente que defende a igualdade dos gêneros em todos os âmbitos da sociedade.

Avançando a discussão em relação à construção da identidade da mulher na esfera profissional, cabe levantar ainda a questão salarial para o sexo feminino. Sabemos que esse aspecto não tem sido claramente resolvido na sociedade contemporânea. As mulheres desejavam não só ingressar no mercado de trabalho, mas queriam também partilhá-lo com o sexo masculino. Sua vontade foi realizada, mas a igualdade salarial tem se mostrado um sonho difícil de ser alcançado. $\mathrm{Na}$ Austrália, por exemplo, todas as lutas no sentido de uma igualdade salarial para o gênero feminino têm passado pela representação sindical. Apenas sob esse sistema, as mulheres têm recebido os salários padrões requeridos e as condições de trabalho necessárias que ajudam a assegurar os seus direitos econômicos nas negociações domésticas. 
Visando à negociação salarial do gênero feminino, Martin (1995: 4, apud Gibson e Graham 1996), diz que a adoção de procedimentos empresariais tem pouco a oferecer à maioria das mulheres porque, no mercado de trabalho desregulado e segregador, elas, em grande número, estão empregadas em firmas pequenas com fraco poder de negociação. O primeiro Relatório Anual sobre Negociação Empresarial (1994) revela que mesmo as mulheres protegidas por acordos registrados e por negociações não-sindicais recebem aumentos salariais menores do que os homens.

Por fim, vale dizer que o trabalho como força estruturante da identidade feminina desempenha papel altamente significativo, pois, se a mulher não trabalhar, nunca atingirá a forma mais expressiva de independência feminina, que só será alcançada pelo poder econômico, o qual é obtido principalmente pelo trabalho. A outra forma de independência, não menos importante, é a conquistada pelo letramento. A mulher, em qualquer cultura, seja ela qual for, deve ter o direito ao conhecimento e aos diferentes modos de ganhar o seu dinheiro, bem como de agregá-lo a sua vida em forma de poder, pois, apenas nessas circunstâncias, a mulher pode se tornar sujeito de seu destino e responsável pela construção de sua identidade.

\section{Considerações finais}

Ao término deste artigo, é pertinente dizer que somente a constituição de um discurso feminino de resistência com poder de desnaturalizar preconceitos, crenças e tabus presentes no discurso masculino poderá construir a nova identidade da mulher contemporânea. Essa deve ser a meta futura do gênero feminino na luta política pela igualdade e emancipação da mulher.

No decorrer do texto, verificamos que é uma inverdade o pensamento freqüente de que a identidade feminina é completa e total. Em cada domínio da vida encontram-se diferentes matizes de sua identidade, cuja plenitude e completude não estarão em nenhum deles. A identidade da mulher é por natureza heterogênea e não se constitui plenamente, mesmo que a reunião de todos os domínios vividos por ela fosse possível. Além disso, a identidade é um processo contínuo e as características identitárias de ontem não constituirão exatamente a identidade de hoje. 
Ao mesmo tempo, a identidade feminina é produto social e reflexo do olhar do outro. Importa, antes de tudo, como e de que modo o outro a vê e não apenas a imagem que ela tem de si mesma. Em qualquer sociedade, a identidade é construída socialmente pelas práticas discursivas, cujo discurso é produto da cultura que a construiu. Assim, a identidade feminina é definida pelo discurso de seu interlocutor. Resulta do efeito espelho, identifica-se pelo reflexo do olhar do outro. Anthony Giddens (2000) levanta a questão de como as condições sociais modernas modificam e modelam o self e a identidade pessoal, criando um novo discurso para a expressão dessa realidade.

Percebemos também que o sexo masculino é o responsável direto pela formação discursiva da identidade da mulher. Qualquer mudança deverá começar pela quebra dos padrões discursivos e pela desnaturalização das crenças e dos comportamentos verbais presentes no discurso masculino sobre a mulher. O primeiro passo para resistir aos comportamentos masculinos de subjugação do gênero feminino deve ser o apagamento das agressões verbais que permeiam as frases quotidianas, tendo em vista que tais práticas discursivas contribuem para enfraquecer os valores identitários femininos. Esses discursos endereçados à figura da mulher com o intuito de depreciá-la devem ser denunciados, para que ela, com o passar dos dias e dos anos, não sofra perdas irreparáveis em sua auto-estima e não seja seriamente comprometida a construção de sua identidade.

O trabalho é outra forma de o gênero feminino resistir aos ataques masculinos a sua identidade, pois o prestígio, sem dúvida, está com quem detém a hegemonia econômica. Afirma Gibson e Graham (1996: 28) "que o capitalismo é uma arquitetura ou estrutura de poder que é conferida pela propriedade e pelo controlo diretivo ou financeiro". Assim, à mulher que não trabalha está destinado o papel de mantida e, por tal razão, a subjugação ao poder do marido.

A luta feminista para a equiparação das mulheres aos homens no que toca ao trabalho não está favorecendo o sexo feminino, ao contrário, está masculinizando-a. O fato de as mulheres trabalharem em igual número de horas que os homens e com as mesmas funções não significa necessariamente a sua libertação; isso pode ser uma dupla escravatura, pois, ao mesmo tempo, trabalha em sua profissão e no lar, duplicando sensivelmente a sua jornada de trabalho. 
Inúmeras mulheres testificam que, ao fim de um dia de trabalho, em diferentes áreas, têm de tomar conta de seus lares enquanto os maridos lêem o jornal diário ou apreciam os programas favoritos de TV. Um movimento de libertação da mulher deve permitir-lhe conservar a cultura própria do seu sexo no mundo do trabalho e da política, o que implica melhores oportunidades profissionais em proporções de igualdade com o sexo masculino, sem diminuir ou perder, no entanto, a qualidade de vida pessoal.

Vale ressaltar que o aumento crescente de mulheres em cargos de responsabilidade tende a multiplicar-se. Assim, cada vez mais o sexo feminino poderá conservar os seus próprios valores, não sendo mais obrigada a adotar os da maioria masculina. De igual modo, o crescimento do número de mulheres em lugares anteriormente ocupados apenas por homens deverá contribuir para que haja mais valores femininos no campo profissional, o que provoca na sociedade o aumento considerável de valores como compreensão e solidariedade.

Com a globalização e com o uso das tecnologias e da automação no trabalho, está surgindo um espaço de trabalho diferenciado cuja essência é o contato humano, ocupações como supervisão, entretenimento, fazer companhia às pessoas e ouvi-las, cuidar delas, ajudá-las material e espiritualmente são um bom exemplo dessas novas tarefas. Nessas funções, apesar dos avanços tecnológicos, a sociedade requer atributos mais femininos como a paciência, a atenção e a intuição. Desse modo, é necessário que a mulher esteja pronta para preencher essas funções.

Para que se instale um discurso de resistência, a palavra de ordem é a adaptabilidade às novas formas de discurso do gênero feminino. Há que transformar o discurso masculino de opressão em discurso de respeito a uma nova mulher: determinada, forte, que adota um projeto reflexivo de vida que implica responsabilidade pessoal. Cada mulher é aquilo que ela faz de si própria, assegura Giddens (1991).

Assim, a identidade feminina na pós-modernidade assume postura, tipicamente, capitalista, independente economicamente, que consome e dita as leis no mercado, inclusive nas relações com o sexo masculino. Não aceita mais ser a escolhida, deseja também ter o direito de escolha com as exigências de quem também detêm o poder em suas mãos. Essa nova mulher trabalha, possui salário próprio, sustenta-se e não depende do sexo masculino para sobreviver. 
A nova identidade da mulher agora se confronta com um mundo instável, em crise de valores, fragmentado, sem direção clara sobre o que ser, o que fazer, o que sentir e pensar, de como viver uma vida significativa e plenamente realizada. Esse novo contexto criado pela pós-modernidade coloca o sujeito diante de uma multiplicidade nunca vista de escolhas e de oportunidades, traz também à cena a possibilidade de análise, do autoconhecimento da mulher, do seu corpo, da sua vida e do que fazer dela. Traz também indicações de como se relacionar com o outro e uma nova concepção de destino como algo aberto, a ser preenchido pela interação de desejos e de liberdades da vida de cada um.

Ao término deste artigo, acresce dizer ainda que, apesar das discussões e dos avanços políticos do gênero feminino na disputa da igualdade de oportunidades e de tratamento, a influência do discurso masculino na construção da identidade da mulher da pós-modernidade é ainda extremamente forte, pois o poder, representado por esse gênero, é concreto e estabilizado ao longo do tempo, de difícil desconstrução e mudança. E, ainda que a identidade feminina decorra da construção discursiva, os seus contornos identitários dependem mais de influências de valorações masculinas do que femininas. Daí porque se afirmar que, numa visão de alteridade, devem ser mudadas as práticas discursivas masculinas a respeito da mulher, para que ela possa plenamente construir-se em outra direção, assumindo a sua verdadeira identidade feminina.

E-mail: josenia@unb.br

\section{REFERÊNCIAS Bibliográficas}

Barton, D. \& Hamilton, M. 1991. Writing in the community. Written communication Annual. London: Sage Publications.

Bourdieu, P. 1994. Raisons pratiques. Sur la théorie de l'action. Paris:Édtions du Seuil.

Cornes, S. 1994. Gender-engedered literacy. In: M. Hamilton, M., D. Barton and R. Ivanic (eds.) Worlds of Literacy. UK: Frankfurt Lodge.

Fairclough, N. 1997. Critical discourse analysis in the 1990s: challenges and responses. ln: Emilia Ribeiro Pedro (org.) Discourse Analysis Proceedings of the 1st Internacional Conference On Discourse Analysis. Lisboa: Edições Colibri. 
Foucault, M. 1985. História da sexualidade 1: a vontade de saber. $7^{a}$ edição. Rio de Janeiro: Graal.

Gibson, K. E Graham, J. 1996. The end of capitalism as we knew it: a feminist critique of political economy. Lisboa: Instituto Piaget.

Giddens, A. 2000. Mundo em descontrole - o que a globalização está fazendo de nós. Rio de Janeiro: Record.

. 2002. Modernidade e identidade. Rio de Janeiro: Jorge Zahar Editor. . 2000. Sociologia. $2^{a}$.edição. Lisboa: Fundação Calouste Gulbenkian.

Hofstede, G. 1991. Culturas e organizações: compreender a nossa programação mental. Lisboa: Edições Silabo.

Marcus, S. 1992. Fighting bodies, fighting words: a theory and politics of rape prevention. In: J. Butler e J. Scott (ed.) Feminist Theorize the Political. Londres e Nova lorque: Routledge: 384-403.

Pedro, E. Ribeiro. 1997. The unbearable lighteness of being. In: Emilia Ribeiro Pedro, E. Ribeiro. (Org.). Discourse Analysis Proceedings of the 1st International Conference On Discourse Analysis. Lisboa: Edições Colibri. Portos. S. D. 1999. Sexo, afeto e era tecnológica. Brasília: Editora da UnB.

Rose, D. 1989. A feministe perspective on employment and gentrification: the case of Montreal. In: J. Wolch e M. Dear (ed.) The Power of Geography: how territory'y shapes social life. Boston: Unwin Hyman: 118-38.

Тацвот, M. 1998. Language and gender: an introduction. Cambridge: Polity Press.

Saegert, S. 1980. Masculine cities and feminine suburbs. Signs 5 (3): 96-111.

Wilson, E. 1991. The Sphinx in the City: urban life, the control of disorder, and women. Londres: Virago Press.

Woodward, K. 1997. Identity and difference. London: Sage Publications. 